\title{
Evaluation of Routine HIV Opt-Out Screening and Continuum of Care Services Following Entry into Eight Prison Reception Centers - California, 2012
}

\author{
Kimberley D. Lucas, $\mathrm{MPH}^{1}$; Valorie Eckert, $\mathrm{MPH}^{2}$; Czarina N. Behrends, $\mathrm{PhD}^{2}$; Charlotte Wheeler, $\mathrm{MD}^{1}$; \\ Robin J. MacGowan, $\mathrm{MPH}^{3}$; Janet C. Mohle-Boetani, MD ${ }^{1}$
}

Early diagnosis of human immunodeficiency virus (HIV) infection and initiation of antiretroviral treatment (ART) improves health outcomes and prevents HIV transmission $(1,2)$. Before 2010, HIV testing was available to inmates in the California state prison system upon request. In 2010, the California Correctional Health Care Services (CCHCS) integrated HIV opt-out screening into the health assessment for inmates entering California state prisons. Under this system, a medical care provider informs the inmate that an HIV test is routinely done, along with screening for sexually transmitted, communicable, and vaccine-preventable diseases, unless the inmate specifically declines the test. During 2012-2013, CCHCS, the California Department of Public Health, and CDC evaluated HIV screening, rates of new diagnoses, linkage to and retention in care, ART response, and post-release linkage to care among California prison inmates. All prison inmates are processed through one of eight specialized reception center facilities, where they undergo a comprehensive evaluation of their medical needs, mental health, and custody requirements for placement in one of 35 state prisons. Among 17,436 inmates who entered a reception center during April-September 2012, 77\% were screened for HIV infection; 135 (1\%) tested positive, including $10(0.1 \%)$ with newly diagnosed infections. Among the 135 HIV-positive patient-inmates, 134 (99\%) were linked to care within 90 days of diagnosis, including 122 (91\%) who initiated ART. Among 83 who initiated ART and remained incarcerated through July 2013, 81 (98\%) continued ART; 71 (88\%) achieved viral suppression (<200 HIV RNA copies/mL). Thirty-nine patient-inmates were released on ART; 12 of 14 who were linked to care within 30 days of release were virally suppressed at that time. Only one of nine persons with a viral load test conducted between 91 days and 1 year post-release had viral suppression. Although high rates of viral suppression were achieved in prison, continuity of care in the community remains a challenge. An infrastructure for post-release linkage to care is needed to help ensure sustained HIV disease control.

Custody records for all new entrants at the state prison reception centers during April-September 2012 were merged with CCHCS laboratory and pharmacy data to obtain records of HIV tests performed within 14 days of entering custody, as well as ART initiation dates. Baseline and follow-up CD4 and viral load tests conducted during April 2012-July 2013 were compared. Patient-inmates were considered to have newly diagnosed HIV infection if there was no previous documentation of an HIV diagnosis in the medical chart or the California enhanced HIV/acquired immunodeficiency syndrome (AIDS) reporting system (eHARS; a browser-based application used to report HIV/AIDS surveillance data to CDC). Patient-inmates with CD $4<200$ cells $/ \mathrm{mm}^{3}$ or an opportunistic infection reported in eHARS within 3 months of HIV diagnosis were considered to have Stage 3 disease (AIDS). Linkage to care in prison was defined as receiving a CD4 or viral load test within 90 days of HIV diagnosis. Patient-inmates who initiated ART within 6 months of HIV diagnosis were classified as having initiated treatment during incarceration, whereas inmates who had ART dispensed before HIV screening or who had an undetectable viral load before ART initiation in prison were classified as continuing treatment at entry. To determine ART response among persons who remained incarcerated, the proportion of persons with undetectable viral load and the median CD4 level at baseline were compared with most recent tests. Medical chart ART records were reviewed to evaluate retention in care while incarcerated. To estimate linkage to care in the community, records of patient-inmates released to the community on ART were matched with eHARS. Because prisons provided patient-inmates a 30-day supply of ART medication at release, uninterrupted care post-release was defined as being linked to care within 30 days. The chi-square test was used to determine associations between categorical variables. The Wilcoxon rank-sum test was used to compare means. A p-value $\leq 0.05$ was considered statistically significant. Analyses were conducted through program evaluation, in collaboration with public health agencies, using routinely collected data following the change in CCHCS policy for HIV screening among California state prison inmates, and were therefore exempt from institutional review board review.

Among 17,436 inmates who entered the prison reception center, 13,388 (77\%) were screened for HIV, including 80\% in the one women's reception center and $77 \%$ in the seven men's reception centers (range $=47 \%-93 \%) ; 135(1 \%)$ inmates were identified as HIV-infected and $10(0.1 \%)$ had newly diagnosed infection (Table 1). Among all HIV-infected patientinmates, 134 (99\%) were linked to care in prison (including one for whom ART was immediately dispensed at entry); one patient-inmate who was released on parole within a week was not linked. Although none of the 10 patient-inmates with 
Morbidity and Mortality Weekly Report

TABLE 1. HIV opt-out screening rate, by gender and reception center (RC) facility - California, April-September 2012 $(\mathrm{N}=17,436)$

\begin{tabular}{|c|c|c|c|c|c|}
\hline & Evaluations & Screened & HIV-positive & $95 \% \mathrm{Cl}^{*}$ & New HIV diagnoses \\
\hline RC facility & No. & No. (\%) & No. (\%) & (\%) & No. (\%) \\
\hline Total & 17,436 & $13,388(76.8)$ & $135(1.0)$ & $(0.9-1.2)$ & $10(0.1)$ \\
\hline Men (total) & 16,301 & $12,481(76.6)$ & $129(1.0)$ & $(0.9-1.2)$ & $8(0.1)$ \\
\hline RC 1 & 1,188 & $1,104(92.9)$ & $9(0.8)$ & $(0.4-1.5)$ & $1(0.1)$ \\
\hline $\mathrm{RC} 2$ & 5,941 & $4,852(81.7)$ & $64(1.3)$ & $(1.0-1.7)$ & $3(0.1)$ \\
\hline $\mathrm{RC} 3$ & 5,589 & $4,231(75.7)$ & $50(1.2)$ & $(0.9-1.6)$ & $4(0.1)$ \\
\hline RC 4 & 2,026 & $1,510(74.5)$ & $4(0.3)$ & $(0.1-0.7)$ & $0(-)$ \\
\hline RC 5 & 320 & $185(57.8)$ & $2(1.1)$ & $(0.1-3.9)$ & $0(-)$ \\
\hline RC 6 & 1,023 & $498(48.7)$ & $0(-)$ & $(0.0-0.1)$ & $0(-)$ \\
\hline RC 7 & 214 & $101(47.2)$ & $0(-)$ & $(0.0-3.6)$ & $0(-)$ \\
\hline Women (RC 1) & 1,135 & 907 (79.9) & $6(0.7)$ & $(0.2-1.4)$ & $2(0.2)$ \\
\hline
\end{tabular}

Abbreviation: HIV = human immunodeficiency virus.

* Exact binomial 95\% confidence interval.

newly diagnosed HIV infection had CD $4<200$ cells $/ \mathrm{mm}^{3}$, two $(20 \%)$ had Stage 3 disease. Among 125 patient-inmates who had previously received a diagnosis of HIV infection, 48 (38\%) had a detectable viral load and 18 (14\%) had CD4 $<200$ cells $/ \mathrm{mm}^{3}$. Linkage to care took significantly longer for patient-inmates with newly diagnosed infection (median $=28$ days; range $=0-35$ days) than for patient-inmates with previously diagnosed infection (median $=0$ days; range $=$ 0-36 days; $\mathrm{p}<0.0001$ ). Excluding the one paroled patientinmate, $91 \%$ of patient-inmates initiated ART, including seven (78\%) with newly diagnosed infection and 115 (92\%) with previously diagnosed infection. Among 43 patient-inmates with CD4 <350 cells $/ \mathrm{mm}^{3}, 40(93 \%)$ initiated ART and three $(7 \%)$ refused; $82(90 \%)$ of 91 patient-inmates with CD4 $\geq 350$ cells $/ \mathrm{mm}^{3}$ initiated ART (Table 2). Among 23 patient-inmates who initiated ART while incarcerated, none had an undetectable viral load at baseline, whereas 19 (83\%) had an undetectable viral load at the latest monitoring test

TABLE 2. CD4 cell count and antiretroviral (ART) treatment initiation among HIV-infected patient-inmates, overall and by HIV diagnosis status and CD4 cell count —California, April 2012-July $2013(\mathrm{~N}=134)$

\begin{tabular}{|c|c|c|c|c|}
\hline \multirow[b]{3}{*}{ Characteristic } & \multicolumn{2}{|c|}{ Previous HIV diagnosis } & \multicolumn{2}{|c|}{ New HIV diagnoses } \\
\hline & & ART initiated & & ART initiated \\
\hline & No. & No. (\%) & No. & No. (\%) \\
\hline All* & 125 & $115(92)$ & 9 & $7(78)$ \\
\hline \multicolumn{5}{|l|}{ CD4 cell count ${ }^{\dagger}$} \\
\hline$<350$ & 39 & $36(92)^{\S}$ & 4 & $4(100)$ \\
\hline $350-499$ & 34 & $32(94)$ & 1 & $1(100)$ \\
\hline$\geq 500$ & 52 & $47(90)$ & 4 & $2(50)$ \\
\hline
\end{tabular}

Abbreviation: HIV = human immunodeficiency virus.

* Includes one patient-inmate with a previous HIV diagnosis started on ART without baseline CD4 cell count or viral load tests; excludes one patient-inmate who was paroled in 6 days without CD4 cell count and viral load testing.

† California Correctional Health Care Services HIV Care Guide (March 2011) required offer of HIV treatment to patient-inmates with CD4 cell count $<350$, consideration of treatment if CD4 cell count 350-500, noted that some experts recommend treatment if CD4 cell count $>500$ cells $/ \mathrm{mm}^{3}$.

$\S$ Three patient-inmates with CD4 cell counts of 25,38 , and 301 cells $/ \mathrm{mm}^{3}$ refused treatment.
( $p<0.0001)$, and CD4 increased by a median of 160 cells/ $\mathrm{mm}^{3}(\mathrm{p}<0.0001)$ (Table 3).

Among 83 patient-inmates who initiated ART and remained incarcerated, 81 (98\%) were on ART at the end of the follow-up period, and $71(88 \%)$ achieved viral suppression. Thirty-nine patient-inmates were released on ART, among whom 14 (36\%) had uninterrupted linkage to care, $11(28 \%)$ were linked within 31-90 days, 10 (26\%) were linked within 91 days-1 year, and four were not linked (i.e., lost to care). Among 33 who had a viral load test after release from prison, viral suppression was achieved at the time of linkage or within 30 days for 12 (86\%) of 14 with uninterrupted care, eight $(80 \%)$ of 10 who were linked to care within 90 days, and one (11\%) of nine linked to care within 1 year. Among those with treatment interruption, 10 (53\%) of 19 with a viral load test performed at the time of linkage to care in the community were not virally suppressed. Among 26 persons with a provider facility reported, eight (31\%) were linked to care after incarceration at a county jail, and 14 (54\%) were linked at a county or non-profit outpatient HIV specialty clinic.

\section{Discussion}

This assessment of prison HIV opt-out screening is the first known to evaluate the full HIV continuum of care outcomes, including opt-out screening during the medical assessment at entry, linkage to and retention in care, ART response during incarceration, and continuity of care and viral suppression after release to the community.

Routine screening identifies asymptomatic persons who are unaware of their infection and might therefore transmit HIV to others. During April-September 2012, HIV opt-out screening at entry into California state prisons identified 10 patient-inmates with new diagnoses of HIV infection. The reported screening rate of $77 \%$ in California is lower than that in the Washington prison system $(90 \%)$ but falls within the higher range among correctional facilities nationwide $(22 \%-98 \%)(3-7)$. The prevalence of new HIV diagnoses $(0.1 \%)$ is comparable to that in other correctional opt-out screening programs (3-7). Eight 
TABLE 3. Change in proportion of HIV-infected patient-inmates with undetectable HIV viral load following antiretroviral (ART) initiation, by ART status at entry - California, April 2012-July 2013 ( $\mathrm{N}=122)$

\begin{tabular}{|c|c|c|c|c|}
\hline \multirow[b]{3}{*}{ ART status at entry } & \multicolumn{4}{|c|}{ No. (\%) with undetectable HIV viral load } \\
\hline & \multirow{2}{*}{$\frac{\text { Baseline }}{\text { No. (\%) }}$} & \multirow{2}{*}{$\begin{array}{c}\begin{array}{c}\text { Initial } \\
\text { monitoring* }\end{array} \\
\text { No. (\%) }\end{array}$} & \multicolumn{2}{|c|}{$\begin{array}{c}\text { Latest } \\
\text { monitoring }\end{array}$} \\
\hline & & & No. (\%) & $(95 \% \mathrm{Cl})^{\S}$ \\
\hline Not on ART $(n=23)$ & $0(-)$ & $7(30)^{9}$ & $19(83)^{* *}$ & (61-95) \\
\hline $\begin{array}{l}\text { Newly diagnosed } \\
\text { infection }(n=7)\end{array}$ & $0(-)$ & $3(43)$ & $6(86)$ & $(42-100)$ \\
\hline $\begin{array}{l}\text { Previously diagnosed } \\
\text { infection }(n=16)\end{array}$ & $0(-)$ & $4(25)$ & $13(81)$ & $(54-96)$ \\
\hline Continuing ART $(n=99)^{+\dagger}$ & $76(77)$ & $74(79)^{\S \S}$ & $71(76)^{\S \S}$ & $(66-84)$ \\
\hline
\end{tabular}

Abbreviation: $\mathrm{HIV}=$ human immunodeficiency virus.

* First HIV viral load following ART initiation.

† Latest HIV viral load among patient-inmates with $\geq 1$ monitoring test; 16 patient-inmates had baseline viral load only.

$\S$ Exact binomial $95 \%$ confidence interval of the latest monitoring test result.

II Initial versus baseline: $p=0.01$.

** Latest versus baseline: $p<0.0001$.

${ }^{+\dagger}$ Excludes one patient-inmate who was not dispensed ART within 6 months of the HIV-positive test.

$\S \S$ Five patient-inmates continuing ART at entry had baseline viral load only.

(80\%) patient-inmates with newly diagnosed HIV infection were identified before developing AIDS, similar to the $76 \%$ reported statewide in California in 2012 (8).

The CCHCS HIV opt-out screening program demonstrated that identifying HIV infection at entry resulted in high rates of linkage to care, retention on ART, and significant reduction in viral loads during incarceration. However, continuity of care in the community remains a challenge for persons with a history of incarceration. Despite prerelease planning, including assigning a case worker during the 90 days before the expected release date and providing information about clinic and community resources, two thirds of patient-inmates released on ART experienced treatment interruption, half of whom were not virally suppressed when linked to care (31 days-1 year); this increases the likelihood of poor clinical outcomes and transmission to others $(1,2)$. A recent study among HIV-infected inmates released from Texas state prisons determined that only $5 \%$ filled their ART prescriptions before exhausting the 10-day supply of medications provided at release (9). In contrast, a study of HIV patients receiving care at a post-incarceration clinic after release from New York City jails identified $86 \%$ as still in care after 6 months (10). The $88 \%$ viral suppression among persons with uninterrupted care after release from a California prison suggests that continuity of care could lead to improved clinical outcomes and prevention of transmission from this population at high risk.

The findings in this report are subject to at least three limitations. First, HIV screening rates varied by reception center, potentially resulting in missed opportunities for HIV diagnoses. Patient-inmates with HIV infection entering the prison system might be underestimated because $23 \%$ of inmates were not

\section{Summary \\ What is already known on this topic?}

Routine HIV opt-out screening during the health assessment at entry into correctional facilities is associated with higher testing rates and new diagnoses of HIV infection than when using opt-in or risk-based screening methods. Earlier reports have indicated that viral suppression rates achieved during incarceration were not sustained after release to the community.

What is added by this report?

This evaluation of HIV opt-out screening at entry into the California state prison system examined the full spectrum of care and identified high rates of in-custody linkage to care (99\%), retention in care (98\%), and viral suppression (88\%) for persons who remained incarcerated. Sustained viral suppression among 12 (86\%) of 14 persons with uninterrupted care following release from prison is evidence that both treatment, and thus prevention of transmission, is achievable on a statewide level.

What are the implications for public health practice?

Supporting continuity of care through actively engaging stakeholders and community partners (e.g., parole and probation agencies, community health care providers, and local health departments) in communication and coordination of medical and social services following release to the community is needed to help ensure sustained HIV disease control.

screened at entry. Second, it is not known whether those who refused an HIV test upon entry differed in terms of demographic or HIV risk behaviors from those who were screened. Finally, the estimated time to linkage to care after release from prison might be inaccurate because of incomplete or delayed laboratory reporting in California.

Routine HIV opt-out screening at entry into California prisons achieved high rates of linkage to care, retention on ART, and viral suppression while incarcerated, but after release, only one third of patients had uninterrupted care. Integration of HIV opt-out screening into the prison medical assessment might result in improved health of persons with HIV and prevention of onward transmission. This service might have the highest impact in communities with a high prevalence of HIV infection. Effective linkage to care systems between the correctional facility and community services are needed to maintain the health benefits gained by HIV-infected patient-inmates while incarcerated. Supporting continuity of care through actively engaging stakeholders and community partners (e.g., parole and probation agencies, community health care providers, and local health departments) in communication and coordination of medical and social services after release to the community is needed to help ensure sustained HIV disease control. 


\section{Acknowledgments}

Lesley Carmichael, DO; John Dunlap, DO; California Correctional Health Care Services.

${ }^{1}$ Public Health Branch, California Correctional Health Care Services; ${ }^{2}$ Office of AIDS, Center for Infectious Diseases, California Department of Public Health; ${ }^{3}$ Division of HIV/AIDS Prevention, National Center for HIV, Viral Hepatitis, STD, and TB Prevention, CDC.

Corresponding author: Kimberley D. Lucas, Kimberley.Lucas@cdcr.ca.gov, 916-628-5977.

\section{References}

1. Cohen MS, Chen YQ, McCauley M, et al.; HPTN 052 Study Team. Prevention of HIV-1 infection with early antiretroviral therapy. N Engl J Med 2011;365:493-505. http://dx.doi.org/10.1056/NEJMoa1105243

2. Hall HI, Holtgrave DR, Maulsby C. HIV transmission rates from persons living with HIV who are aware and unaware of their infection. AIDS 2012;26:893-6. http://dx.doi.org/10.1097/QAD.0b013e328351f73f

3. CDC. HIV screening of male inmates during prison intake medical evaluation-Washington, 2006-2010. MMWR Morb Mortal Wkly Rep 2011;60:811-3.
4. CDC. Routine HIV screening during intake medical evaluation at a county jail-Fulton County, Georgia, 2011-2012. MMWR Morb Mortal Wkly Rep 2013;62:495-7.

5. Beckwith CG, Nunn A, Baucom S, et al. Rapid HIV testing in large urban jails. Am J Public Health 2012;102(Suppl 2):S184-6. http:// dx.doi.org/10.2105/AJPH.2011.300514

6. Beckwith CG, Bazerman L, Cornwall AH, et al. An evaluation of a routine opt-out rapid HIV testing program in a Rhode Island jail. AIDS Educ Prev 2011;23(Suppl 3):96-109. http://dx.doi.org/10.1521/ aeap.2011.23.3_supp.96

7. CDC. Routine jail-based HIV testing-Rhode Island, 2000-2007. MMWR Morb Mortal Wkly Rep 2010;59:742-5.

8. CDC. Monitoring selected national HIV prevention and care objectives by using HIV surveillance data-United States and 6 dependent areas-2012. HIV Surveillance Supplemental Report. Atlanta, GA: US Department of Health and Human Services, CDC; 2014. http://www. cdc.gov/hiv/pdf/surveillance_report_vol_19_no_3.pdf

9. Baillargeon J, Giordano TP, Rich JD, et al. Accessing antiretroviral therapy following release from prison. JAMA 2009;301:848-57. http:// dx.doi.org/10.1001/jama.2009.202

10. Fox AD, Anderson MR, Bartlett G, Valverde J, Starrels JL, Cunningham $\mathrm{CO}$. Health outcomes and retention in care following release from prison for patients of an urban post-incarceration transitions clinic. J Health Care Poor Underserved 2014;25:1139-52. http://dx.doi.org/10.1353/ hpu.2014.0139 